\title{
De la crueldad activa: lecturas de Nietzsche en la obra de Leopoldo María Panero
}

\section{Of Active Cruelty: Readings of Nietzsche in the Works of Leopoldo María Panero}

Joaquín Ruano

Ludwig-Maxilians-Universität München

jruanocespedes@gmail.com

\section{Resumen:}

El presente artículo aborda, desde una perspectiva crítica, la importancia de los textos de Friedrich Nietzsche en la obra del poeta Leopoldo María Panero, y cómo estas lecturas configuran uno de los soportes principales a la hora de elaborar una estética y una epistemología basada en el ataque y la transgresión de los sistemas morales establecidos.

Palabras clave: Leopoldo María Panero, Friedrich Nietzsche, literatura y mal, transgresión, valores morales.

\section{Abstract:}

This article tackles, from a critical perspective, the importance of Friedrich Nietzsche's writings in Leopoldo María Panero's works and how these readings are one of the most important basis in the Spanish poet's creation of an aesthetics and an epistemology based on attack and transgression of the established moral systems.

Keywords: Leopoldo María Panero, Friedrich Nietzsche, Literature and Evil, Transgression, Moral Values. 
La escritura de Leopoldo María Panero traza el mal, recorre con sus versos hirientes las más oscuras partes del ser humano, mostrándolas, indagando aun más en la herida hasta hacerla reventar, hasta hacer gemir los goznes de los que clausuran no solo todo lo pensable, sino incluso todo lo decible. Pero la escritura de Leopoldo María Panero no es solo estéticamente cruel, sino que también lo es epistemológicamente. La crueldad y la sangre de Panero tienen un trasfondo: son una poética del mal que bebe en lo más apartado, en lo más prohibido de las bibliotecas para darse (una) entidad en un mundo que se hace de citas. Con él se recorre la crueldad de la literatura (de una literatura) que enarbola el mal como rebeldía, como terrorismo. Sin embargo, la escritura de Panero no es una escritura de muerte, negativa, sino una escritura activa; recordemos que ya su primera poética se construía en torno a la sentencia "un crepúsculo activo: un asesinato" (cit. en Castellet 240). La muerte nunca es el final en la mecánica de la transgresión de la escritura paneriana. Es el caso de "Glosa a un epitafio (Carta al padre)", donde la muerte del padre es el punto de partida para comenzar una relación que conjuga incesto y necrofilia:

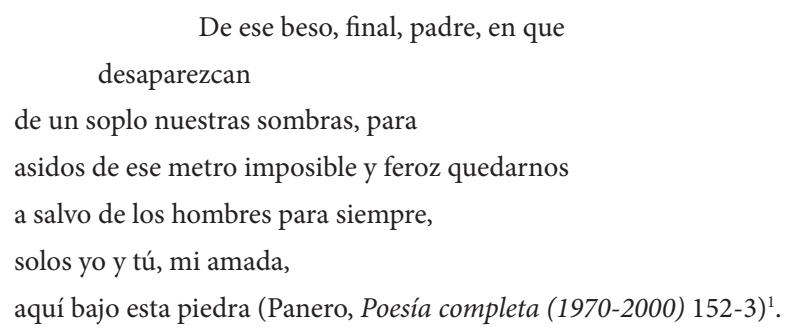

Para desentrañar el sentido del mal en sus páginas, por tanto, Panero nos propone un nuevo Virgilio con el que atravesar, una vez más, el infierno. Una lectura indispensable para completar esa sección terrorífica de su biblioteca. Y, en efecto, la interpretación de la obra de Panero no hubiera tenido sentido, o al menos no un sentido completo, sin acompañar sus versos con la lectura del alemán Friedrich Nietzsche.

Partamos de una sentencia irrefutable: la obra del poeta Leopoldo María Panero, nacido en Madrid en 1948, autor de más de una veintena de libros, e igualmente admirado y odiado por la crítica española, trata sobre el mal. Esto es tan irrefutable como lo es también que dicho discurso no aparece ex nihilo, sino que en su necesidad, en su pulsión de describir lo más terrible, Panero busca, forma, una tradición filosófica y literaria que refuerce sus propias obsesiones (como, en definitiva, hace cada escritor que se precie de serlo). Y, sin embargo, no estamos ante una poesía que se quiera meramente recopilación de conocimientos, sino, muy por el contrario, ante una poesía que no puede entender esos conocimientos como un refuerzo teórico a una práctica política. Una poesía que busca dominar:

1 Para un completo análisis de este poema, es indispensable el texto de Túa Blesa que se incluye en Tránsitos. Escritos sobre poesía (107-21). 
La filosofía reducida a "teoría del conocimiento", y que ya no es de hecho más que una tímida epojística y doctrina de la abstinencia: una filosofía que no llega más que hasta el umbral y que se prohíbe escrupulosamente el derecho a entrar -esa es una filosofía que está en las últimas, un final, una agonía, algo que produce compasión. ¡Cómo podría semejante filosofía- dominar! (Nietzsche, Más allá del bien y del mal 142)².

Estamos, por tanto, ante una escritura que, desde el lenguaje literario, utiliza la inmoralidad para hacer política. Habrá tiempo, en estas páginas, de detallar con mayor precisión qué significa esta voluntad bajo este nuevo prisma de lectura. Ahora, sin embargo, urge dar algunos ejemplos. Pocas páginas de Panero pueden ejemplificar mejor una voluntad política que parte, pero que a la vez trasciende, el mero hecho cognoscitivo. Y es precisamente en el más nietzscheano de los libros de Panero, El último hombre ${ }^{3}$, en el que encontramos las "Páginas de poesía política". Hacer política no es otra cosa que denunciar, una y otra vez, las situaciones de violencia que el poder (de los hombres) ejerce sobre los hombres, como en el caso del terrorista vasco Eduardo Moreno Bergareche, alias Pertur, el cual desapareció en extrañas circunstancias, y del que se sospecha que murió a manos de grupos de extrema derecha. Precisamente, Panero nos lo presenta hablándonos desde el reino de los muertos en el primer poema del libro, titulado "Réquiem":

Yo soy un hombre muerto al que llaman Pertur.

En la cena de los hombres quién sabe si mi nombre

Algo será: ceniza en la mesa

O alimento para el vino [...] (Poesía completa (1970-2000) 291).

Y en esta denuncia política no falta uno de los hitos generacionales de Panero, la guerra de Vietnam, la cual -si bien terminada ocho años antes de la publicación del libro que estamos tratando- deja su presencia en dos poemas. En el primer caso, "Sueño de una noche de verano", se nos narra la atmósfera pesadillesca de un soldado en la selva, como imagen que vuelve una y otra vez a un antiguo combatiente:

Los hombres del Viet son tan hermosos cuando mueren.

El agua del río, lamiendo sus piernas, hacía más sexual su ruina.

Luego vinieron las Grandes Lluvias buscando la vagina hambrienta de la selva y todo lo borraron. Quedó solo en los labios la sed de la batalla, para nada, como baba

que cae de la boca sin cerebro.

2 Salvo que se indique lo contrario, las cursivas son del autor.

3 El último hombre (incluido en Poesía completa (1970-2000)) es un título que Panero toma de Así habló Zaratustra: "Voy a hablarles de lo más despreciable: el último hombre. [...]iAy! Llega el tiempo en que el hombre no dará ya ninguna estrella. ¡Ay! Llega el tiempo del hombre más despreciable, el incapaz ya de despreciarse a sí mismo. ¡Mirad! Yo os muestro al último hombre” (34-5). 
Hoy

que en lecho sin árboles ni hojas

con tu lengua desnudas el árbol de mi sexo

y cae toda la noche el semen como lluvia

y cae toda la noche el semen como lluvia, dime

besando suavemente el túnel de mi ano,

cueva de la anaconda que aún me marca

los ritmos de la vida, dime qué era, qué es,

qué es un cadáver (Poesía completa (1970-2000) 294).

O en el poema "Soldado herido en el lejano Vietnam", donde se presenta el trauma del que ha sufrido las consecuencias de la guerra, persona que ha quedado ya inhabilitada para poder vivir, marcada para siempre por el horror de la batalla:

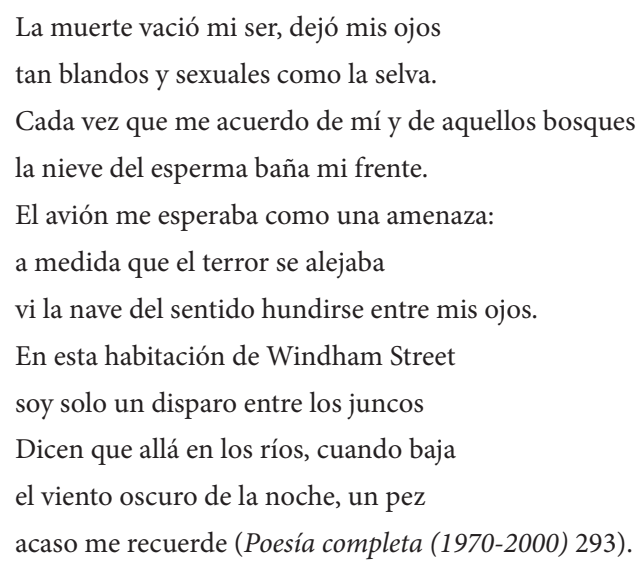

Sin embargo, la política paneriana no es una poesía política hecha al uso y al servicio simplemente de la (mayor o menor) actualidad, sino que para nuestro autor hacer política significa, más allá de denunciar una situación concreta, denunciar la propia condición humana; y, para ello, sus "Páginas de poesía política" se llenarán de ejemplos que rompen con el aquí y ahora, con el tiempo y el espacio presentes, para convertirse en una denuncia eterna. De este modo, es en "La noche del soldado en la casa abandonada" donde se nos cuenta la angustia de un soldado en una guerra sin duda anterior al conflicto de Vietnam:

[...] Temo morir.

Temo morir más que en la batalla temo perder el ser, vencida la batalla por medio de este ruido sigiloso.

Temo que caiga el nombre

como del muro

el revoco, el papel, el dibujo. ¿Qué es la noche?

¿Qué es el búho? ¡Si un perro ladrara! 


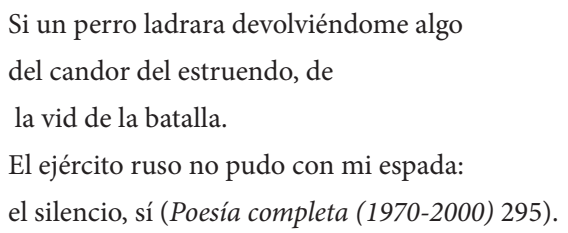

Tampoco se ciñe su poesía política al discurso antibelicista en el cual se nos presenta al individuo a la vez como víctima y títere de un proceso injusto, sino que también encontramos que la denuncia se traslada a la represión que el poder ejerce sobre los que no están conformes con su ley, como cuando se nos presenta al líder indígena Tupac Amaru, torturado brutalmente hasta su ejecución a finales del siglo XVIII:

Busco aún mis ojos en la Mano

en la Mano y en el suelo,

y recuerdo que fui hombre,

antes

de que el metal hiciera arder mi cuerpo [...] (291).

Pero quizás el ejemplo más significativo de lo que representa la poesía política para Panero lo encontraremos en los dos poemas que le dedica al hereje alemán Thomas Müntzer, la espada de Dios, figura en la cual el mesianismo y la concepción revolucionaria se aúnan. En el primero de ellos, “Thomas Müntzer, teólogo de la liberación”, Panero contrapondrá la fe pura, la pasión del iluminado de Müntzer, al fariseísmo de biblioteca de Lutero, quien se hizo con la supremacía en una época llena de herejías:

Quemaban a los ricos con antorchas

y tal que la hierba seca ardían sus cuerpos.

Que el clero, con sus falsas oraciones

te consuelen de desaparecer.

Todos los hombres se creían dios.

Mataban y luego eran despedazados.

Lutero maneja con mayor elegancia los libros:

su mano no trabajó nunca sabe

mover las páginas y engañar a los hombres.

Müntzer tiene la pasión y no la idea:

sin duda morirá despedazado (Poesía completa (1970-2000) 295-6).

El segundo poema, "La palabra, el hecho (teoría y praxis)", presenta un corte mucho más vanguardista. Dividido, como su título indica, en dos partes, en la primera se nos muestra mediante imágenes el incendiario discurso salvacionista de Müntzer:

I - la palabra

(Discurso de Thomas Müntzer a las masas)

El mundo se divide en dos: 
los hombres de la carne y los hombres del verbo.

Cuando la palabra cae en la pradera

es llama (Poesía completa (1970-2000) 296).

En la segunda parte se impone la realidad; tras la fascinación de las llamas del discurso, solo quedan las cenizas de la derrota del 15 de mayo de 1525. El revolucionario ha sido, una vez más, reprimido, y el polvo del olvido se extiende sobre él:

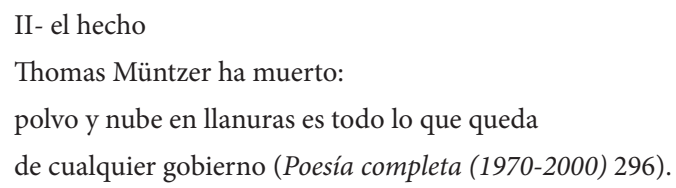

Más allá del mero ejercicio político, la obra de Leopoldo María Panero se interesa por la represión que ejerce un sistema moral injusto que impone por todos los medios, aun los más crueles, sus creencias. Pero, como decíamos antes con el saber, esta denuncia no se queda en la simple enunciación de hechos pavorosos ejercidos por la mecánica implacable del poder, sino que va mucho más allá y se propone, siguiendo la estela nietzscheana, cuestionar la propia noción de moral:

La moral es únicamente una interpretación (Ausdeutung) de ciertos fenómenos, dicho de una manera más precisa, una interpretación equivocada (Missdeutung). El juicio moral, lo mismo que el juicio religioso corresponde a un nivel de ignorancia en el que todavía falta el concepto de lo real, la distinción entre lo real y lo imaginario: de tal manera que, en ese nivel, la palabra "verdad" designa simplemente cosas que hoy nosotros llamamos “imaginaciones" (Nietzsche, Crepúsculo de los ídolos 77).

Una moral que, una vez desnuda, expuesta al escrutinio imparcial, se muestra como un sistema interesado; un corpus legal bajo el que aparecen, a poco que se examine, los verdaderos motivos de su existencia. Y estos motivos no son otros que favorecer los intereses de un grupo concreto, el grupo que domina, no por su vigor y su capacidad para ello, sino del grupo que domina desde su propia debilidad moral, que transforma arteramente el propio significado de las palabras en su beneficio:

Este "malo" (schlecht) de origen noble, y aquel "malvado" (böse), salido de la cuba cervecera del odio insaciado -el primero, una creación posterior, algo marginal, un coloro complementario, el segundo, en cambio, el original, el comienzo, la auténtica acción en la concepción de una moral de esclavos-, ¡cuán diferentes son estas dos palabras, "malo" (schlecht) y "malvado" (böse) que aparentemente se oponen a un mismo concepto "bueno" (gut)! Mas no se trata del mismo concepto "bueno": pregúntese, antes bien, quién es propiamente "malvado" en el sentido de la moral del resentimiento. Contestado con todo rigor: precisamente el "bueno" de la otra moral, precisamente el noble, el poderoso, el dominador, solo que ha cambiado de color, interpretado y visto del revés por el ojo venenoso del resentimiento (Nietzsche, La genealogía de la moral 65). 
El origen de ese resentimiento no es otro que la vergüenza ante la propia debilidad. Una vergüenza y una debilidad que, una vez tomado el poder, quiere imponerse al resto. Se trata de la estrategia, perfectamente calculada, de expandir el asco de uno mismo, la negación del propio cuerpo y las propias fuerzas. El poder de lo débil comienza por una negación de los propios instintos:

La enemistad, la crueldad, el placer en la persecución, en la agresión, en el cambio, en la destrucción - todo esto se ha vuelto contra el poseedor de tales instintos: ése es el origen de la "mala conciencia". El hombre que, falto de enemigos y de resistencias interiores, encajonado en una opresora estrechez y regularidad de las costumbres, se desgarraba, se perseguía, se mordía, se roía, se sobresaltaba, se maltrataba impacientemente a sí mismo, este animal al que se quiere "domesticar" y que se golpea furioso contra los barrotes de su jaula, este ser al que le falta algo, devorado por la nostalgia del desierto, que tuvo que crearse a base de sí mismo una aventura, una cámara de suplicios, una selva insegura y peligrosa -este loco, este prisionero añorante y desesperado fue el inventor de la "mala conciencia" (La genealogía de la moral 141).

Si partimos de la premisa de que el símbolo no es sino un aspecto interno de la religión o, mejor dicho, que la religión recubre lo simbólico del manto de lo cultual para sacralizar (unos) ciertos valores, el símbolo, entonces, es la esencia, la conceptualización de un sistema de creencias que al poder le interesa imponer y conservar. Pues bien, es en este sentido que el concepto de Dios implica la simbolización de esa negación de los instintos, de esa responsabilidad y culpabilidad que el poder de los débiles quiere imponer para justificar su propia enfermedad:

Nadie es responsable de existir, de estar hecho de este o de aquel modo de encontrarse en estas circunstancias o en este ambiente. La fatalidad de su ser no puede ser desligada de lo que fue y será [...] El concepto "Dios" ha sido hasta ahora la gran objeción contra la existencia... Nosotros negamos a Dios, negamos la responsabilidad en Dios: solo así redimimos al mundo (Crepúsculo de los ídolos 75-6).

Son, por tanto, los valores ascéticos los que se encarnan en la imagen de Dios, esos valores que niegan la vida, que la consideran algo mórbido, despreciable, un camino necesario que hay que sufrir antes de llegar a una liberación eternamente prometida y eternamente prolongada hasta el infinito; porque, de lo que se trata aquí es de mantener indefinidamente una esperanza imposible, de tal modo que la masa esté sedada, amansada, dominada, aniquilada, esto es, reducida a la nada:

Dicho una vez más: este instinto depresivo y contagioso obstaculiza aquellos instintos que tienden a la conservación y a la elevación de valor de la vida: tanto como multiplicador de la miseria como conservador de todos los miserables es un instrumento capital para la intensificación de la décadence - ¡La compasión persuade a entregarse a la nada!... No se dice "nada": se dice, en su lugar, "más allá"; o "Dios"; o "la vida verdadera"; o nirvana, redención bienaventuranza... Esta inocente retórica, nacida del 
reino de la idiosincrasia religioso-moral, aparece mucho menos inocente tan pronto como se comprende cuál es la tendencia que aquí se envuelve en el manto de palabras sublimes: la tendencia hostil a la vida (Nietzsche, El Anticristo 36).

Hallamos, por tanto, la maquinaria terrible y despiadada del poder, una maquinaria cuyo objetivo principal es desnaturalizar al hombre, quitarle el goce de sus instintos, lo irredento, la línea de fuga que escapa a toda codificación:

Una vez expulsada del mundo mediante el premio y el castigo la causalidad natural, se requiere una causalidad antinatural: a partir de ahora el resto de cosas se sigue de aquí. Un Dios que exige -en lugar de un Dios que ayuda, que da consejos, que en el fondo es la palabra para designar toda feliz inspiración del valor y de la confianza en sí... La moral, ya no expresión de las condiciones de vida y crecimiento de un pueblo, ya no su instinto vital más hondo, sino convertida en algo abstracto, convertida en antítesis de la vida, -la moral como modo de volver por principio malas las cosas con la fantasía, como "mal de ojo" para todas las cosas. ¿Qué es la moral judía, qué es la moral cristiana? El azar, privado de su inocencia; la infelicidad, manchada con el concepto de "pecado"; el bienestar, considerado como peligro, como "tentación"; el malestar fisiológico, envenenado con el gusano de la conciencia (El Anticristo 59).

Ahora bien, el hombre moderno, el hombre del final de los tiempos, como hemos visto, se rebela ante ese absurdo, ante esa mentira, ante esa contaminación del alma, ante esa dictadura de lo irreal:

Frente a las cosas pasadas soy, al igual que todos los hombres de conocimiento de una gran tolerancia, es decir, de un autodominio magnánimo: yo atravieso con una sombría cautela ese manicomio que ha sido el mundo durante milenios enteros [...] Pero mi sentimiento cambia, estalla, tan pronto como ingreso en la época moderna, en nuestra época. Nuestra época está enterada... lo que en otro tiempo no era más que algo enfermo se ha convertido hoy en algo indecente -es indecente ser hoy cristiano. Y aquí comienza mi náusea (El Anticristo 75).

Esta eterna acusación contra el cristianismo voy a escribirla en todas las paredes -allí donde haya paredes-, tengo letras que harán ver incluso a los ciegos... Yo llamo al cristianismo la única gran maldición, la única grande intimísima corrupción, el único gran instinto de venganza, para el cual ningún medio es bastante venenoso, sigiloso, subterráneo, pequeño, -yo lo llamo la única inmortal mancha deshonrosa de la humanidad... (El Anticristo 121).

Es entonces cuando Panero, ante la maldición de la religión, ante el símbolo de Dios y del cristianismo, elabora otro símbolo: la herejía y, concretamente, la brujería. Esto es, ante Dios, Panero enarbola el culto al Demonio, a lo maligno, como bandera de la liberación del instinto (cfr. Ruano). En la serie "Poemas de la vieja", del libro Guarida 
de un animal que no existe, encontramos quizá el ejemplo más obvio, si bien no el único, de hasta qué punto es capital el tema de la brujería en la obra poética de Panero. La vieja es para el autor madrileño un signo de la brujería queda suficientemente claro cuando leemos estos versos:

Dijo el demonio a la vieja

desnúdate y baila conmigo

muéstrame tu cuerpo fláccido

como una flor se deshoja

también el diablo es viejo

y cual tu culo sonrosado (Panero, Poesía completa (1970-2000) 550).

Desarrollado este ciclo en nueve poemas, se nos muestra la psicología de la bruja, destruida por la decadencia del tiempo:

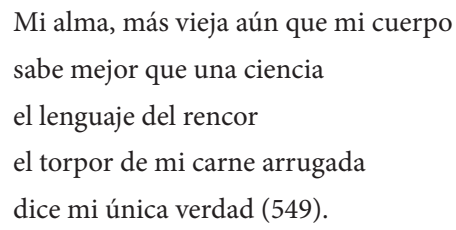

Ahora bien, esta decadencia corporal no hace que las brujas hayan perdido el interés por los placeres de la vida y así, en fiero aquelarre, las viejas fornican con los muertos:

El calor de mi carne inmunda

Solo a los muertos conviene

Pero peor que ser vieja

De cuerpo es serlo de alma,

Aún más inmunda que mi cuerpo (548).

Es así como las brujas se libran al mal, al demonio, en el baile frenético del Sabbat: Las viejas solo sabemos alabar al demonio

de los ángeles nos burlamos

pues nos recuerdan nuestros amores.

Carne arrugada y fofa solo puede ser follada

por el pellejo de una bestia.

Paseando entre las tumbas

gritamos "Papè Satán

Papè Satán Aleppe": y la muerte nos sonríe

alegre como nuestro último baile.

Por la mañana, cuando el sol

sale a perseguir la manada

bailamos con el diablo, y sin dientes

Sonreímos: nada peor que mi sonrisa. 
Y así al demonio le ofrezco

esta ofrenda de hojas secas (549).

Sin embargo, como veremos a continuación, la brujería, la celebración del Sabbat, el ser diferente y perseguir los placeres de la carne y la ebriedad solo puede tener un fin, la hoguera:

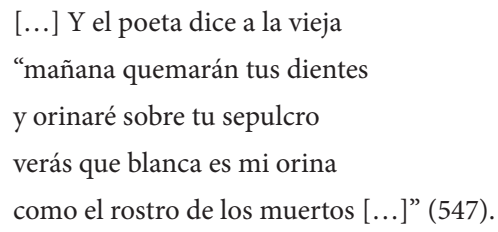

En un principio la brujería se manifestará, históricamente, como una tendencia herética que se materializa como pervivencia, y desarrollo, de las tendencias paganas, sobre todo las que rinden culto a Hécate, deidad grecolatina de la hechicería y las artes ocultas, soberana que se manifiesta en los cruces de caminos, las encrucijadas (Caro Baroja 101). Ahora bien, con el pensamiento escolástico del último tramo de la Edad Media, el eje que separa el paganismo del cristianismo deja de ser vertical, para ser horizontal (97). Esto implica que una de las partes, el cristianismo, se sitúa en el campo superior, mientras que el paganismo pasa a la parte inferior. Un hito en el estudio de la brujería es marcado por la aparición a finales del siglo XV del libro conocido como Malleus Maleficarum (1486), escrito por dos inquisidores destinados en las diócesis del sur de Alemania, los hermanos predicadores Enrique Institor y Jacobo Sprenger. Dividido en tres partes, este texto supone una revolución en la represión del satanismo, al asociarse de manera definitiva la persecución de brujas a la labor de los legisladores, no solo eclesiales, sino también civiles:

Para iniciar una causa basta la acusación de un particular o la denuncia, sin pruebas, hecha por persona celosa. Lo más corriente es, sin embargo, que el juez la abra ante rumor público. En determinados casos puede bastar el testimonio de un niño: también el de ciertos enemigos de la persona acusada. El juicio debe ser sencillo, rápido y definitivo. Al juez se le deben dar plenos poderes: él es el que tiene que decidir si un acusado tiene derecho a defenderse o no, el que elige el abogado defensor, el que pone condiciones que lo convierten más en acusador que en otra cosa. El tormento ha de usarse libérrimamente: si aun en él no declara el reo, es posible admitir que es por encanto diabólico. No se admite la ordalía y casi siempre el final es el mismo. La retractación y el arrepentimiento no libran de la muerte al convicto. El brazo secular se apodera de él, cuando no es la misma justicia secular la que lo condena, pues el crimen de Brujería no es solamente religioso, es también civil (cit. en Caro Baroja 131).

Es esta tipificación siniestra del delito lo que denunciará Panero en su poema "Auto de fe": 
Dios el perro me llama el aire quema a un hombre horizonte dos cuerpos ardiendo intensamente quince ángeles velan donde estuvo mi frente soy el negro, el oscuro: ardiendo está mi nombre. [...]

Es la ley el silencio y también la blasfemia

Es mostrar a los hombres una cruz en la boca

$\mathrm{Y}$ decirles que arde, como cabo de vela

Mi alma en la penumbra como una blasfemia

Dios el mudo, escultura de sombra, florecer de roca

Y los dados de un ciego que cierran el poema (Poesía completa (1970-2000) 307).

Panero, sin embargo, imagina el Sabbat como una celebración de la vida, de la asunción de la muerte que conllevan los placeres prohibidos del sexo, la música y la ebriedad:

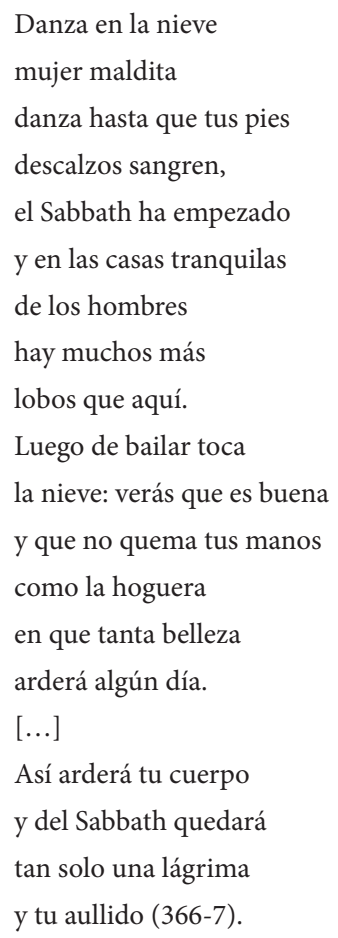

La herejía, por tanto, supone la puesta en cuestión de un saber unitario, parcelado y bien distribuido, en que las ideas pueden ser vigiladas en una cuadrícula donde no caben las disensiones, y la poesía de Panero pone este saber unitario en cuestión, incesantemente, con la fuerza, la constancia y la desesperación del que ha quemado todas las naves tras de él. La herejía significa eso en Panero: la tradición en la que el poeta se apoya para 
expresar su mensaje de transgresión y locura, de traspaso de los límites y de denuncia de la injusticia. Como dice Nietzsche:

Pensar de diferente modo al acostumbrado -es, no tanto el efecto de un intelecto mejor, sino el efecto de impulsos más fuertes y malignos, de impulsos más desatadores, aislantes, porfiados, pérfidos y taimados. La herejía es el paralelo de la brujería y como ésta en modo alguno una cosa inofensiva, y menos una en sí venerable. Los herejes y las brujas son dos tipos humanos malos: tienen en común el sentirse malos, pero no pueden resistir al deseo de hacer mal a lo imperante (hombres u opiniones) (La gaya ciencia 90-1).

Se produce entonces el movimiento de antítesis a la religión del odio y el resentimiento $^{4}$, la reivindicación de los instintos liberados, del discurso que, con su grito, se libera de toda esa atmósfera de cerrazón, de podredumbre, y explota en el deseo dionisiaco. Es el tiempo del cantar alegre, de la gaya ciencia:

"Gaya ciencia": significa esto las saturnales de un espíritu que ha soportado pacientemente una larga y terrible presión [...] y al que invade de golpe la esperanza de la salud, la embriaguez de la curación. No es de extrañar, entonces, que salga a la luz mucha insensatez y locura, mucha ternura traviesa, gastada incluso en problemas espinosos que no están hechos para ser acariciados o seducidos (La gaya ciencia 29).

Es la feliz interpretación de imposiciones ideológicas o morales, el arte que no niega la vida, sus instintos, sino que -muy por el contrario- los afirma, haciendo de ellos el único credo aceptable: "Nuestra religión, nuestra moral y nuestra filosofía son formas de la decadencia del hombre. El 'movimiento opuesto' es el arte" (Nietzsche, La voluntad de poderío 429). Así pues, ese arte es la nueva verdad, la verdad que no es sino la naturaleza que siempre estuvo allí, reprimida, no autorizada a expresarse, pero sí resistiendo a una mordaza tan artificial como perversa. Ese nuevo arte no expresa ninguna ideología ni religión sino la propia, es "un arte diferente - un arte desenfadado, divinamente artificioso que cual llama pura se proyecte en un cielo diáfano ¡sobre todo un arte para artistas, únicamente para artistas!" (La gaya ciencia 35). Así, libre de todo, el discurso artístico -léase aquí poéticoes el verdadero discurso de la gaya ciencia, el canto de Apolo y la danza desenfrenada de Dionisos, la negación de la hipocresía moral y la exaltación del instinto libre. Y ese discurso, nos dice Panero leyendo a Nietzsche, solo puede lograrse mediante la asunción del mal:

[...] solo por cuanto el mal es una subversión del orden o el diablo es la subversión del logos, una subversión nada monarquiana, ni tampoco dualista, sino partidaria de esa Aufhebung del bien y del mal, que está en Nietzsche, cuya revolución era vivir lo que se piensa y pensar lo que se vive, siendo así esa reductio ad hominem lo que nos lleva a presentar al superhombre (Poesía completa (1970-2000) 508-9).

4 "Cristiano es el odio al espíritu, al orgullo, al valor, a la libertad, al libertinage del espíritu; cristiano es el odio a los sentidos, a las alegrías de los sentidos, a la alegría en cuanto a tal” (El Anticristo 53). 
De lo que se trata aquí no es sino de la superación del discurso represivo ascético, de poner en cuestión los valores con un canto del mal que se produce para destruir esa dialéctica falsa que el sistema moral impone. Se trata de terminar con el hombre para llegar al superhombre. Y, para ello, hay que agotar al hombre, terminar con él haciendo que sean sus propios vicios, sus propias mentiras las que los extingan. Es el tiempo del último hombre, el hombre que destruye la moral por colapso, el hombre que enarbola el mal absoluto, la antimoral como oposición a un bien falso, a una moral aplastante:

...necesitamos una crítica de los valores morales, hay que poner alguna vez en entredicho el valor mismo de estos valores -y para esto se necesita tener conocimiento de las condiciones y circunstancias de que aquéllos surgieron, en las que se desarrollaron y modificaron (la moral como consecuencia, como síntoma, como máscara, como tartufería, como malentendido; pero también la moral como causa, como medicina, como estímulo, como freno, como veneno), un conocimiento que hasta ahora ni ha existido ni tampoco se lo ha siquiera deseado (Nietzsche, La genealogía de la moral 32).

Se hace necesario, por consiguiente, encrapularse, tomar todos los vicios y perpetrar todos los crímenes, ser el peor entre los peores. El hombre que canta a la transgresión de unas primeras leyes que fundan toda sociedad, la prohibición del incesto:

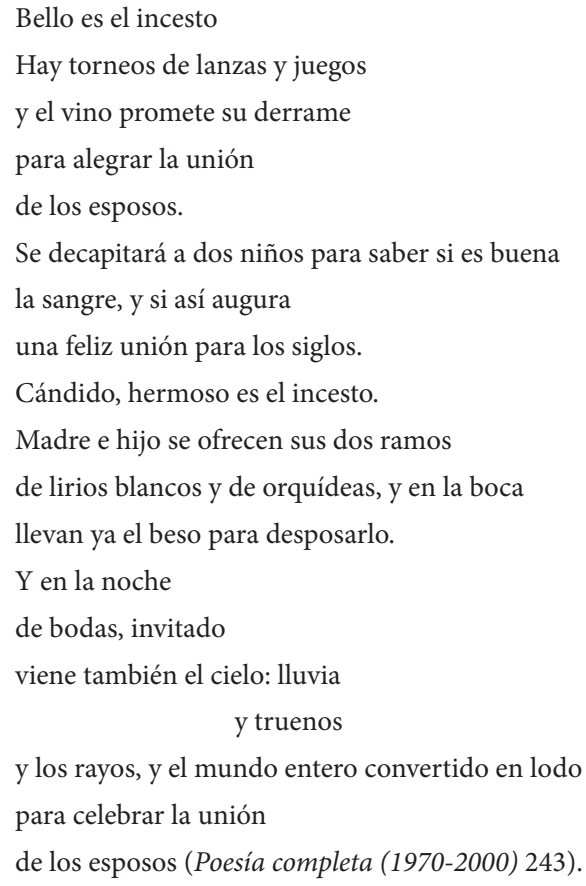

La explosión de los valores no tiene otro objetivo, ya lo hemos dicho, que denunciar una verdad durante mucho tiempo mantenida, una versión de la realidad que intenta hacer del hombre un animal manso, humillado, resentido, sin ideales de auténtica nobleza y con 
instintos pervertidos. No tiene otro objetivo que denunciar los instrumentos de la cultura (Nietzsche, La genealogía de la moral 68-9), la propaganda de esos ideales de corrupción y de negación de lo que está vivo. La explosión de los valores, la subversión del concepto de lo bueno y lo malvado (o de lo bueno y lo malo), es entonces un terrorismo intelectual, físico, pasional y, por supuesto, moral con objetivos perfectamente delimitados:

[...] nosotros opinamos que dureza, violencia, esclavitud, peligro en la calle y en los corazones, ocultación, estoicismo, arte de tentador y diablerías de toda especie, que todo lo malvado, terrible, tiránico, todo lo que de animal rapaz y de serpiente hay en el hombre sirve a la elevación de la especie "hombre" tanto como su contrario [...] (Nietzsche, Más allá del bien y del mal 68).

Se trata, repetimos, de un doble movimiento: por una parte, el desenmascaramiento de la falsedad moral de los grupos de poder; por otra se trata, en la escritura de Leopoldo María Panero (y en la lectura que este hace de Friedrich Nietzsche), de dar rienda suelta a todas las pulsiones, a todos los instintos libidinales, de placer y de muerte, hasta conseguir una sexualidad en la que la búsqueda de la belleza se mezcla con lo horrendo: la vida y el placer con el sufrimiento y el horror; una estética en la que Eros y Tánatos fornican en una orgía humana, demasiado humana:

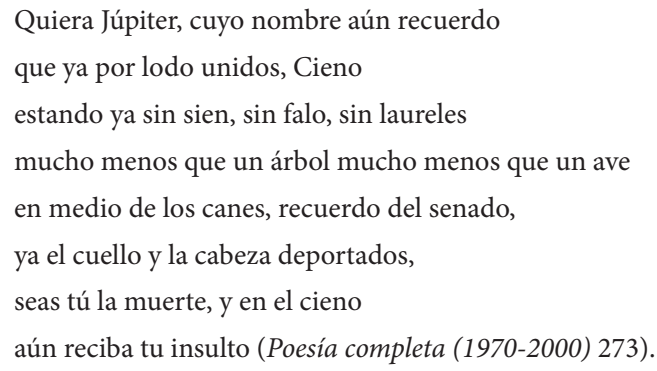

Buscando el mal encontraremos la razón fundamental de la poesía paneriana, basada en la persecución de lo execrable como motivo revolucionario. Es, para Panero, el mal el motor que agita las conciencias, que prepara un nuevo tiempo, el tiempo por venir del superhombre liberado de la esclavitud moral, de la injusticia velada. El mal en la poesía de Panero significa fundamentalmente el signo de un cambio que se presenta como algo a la vez inevitable y urgentemente necesario:

Hasta ahora, los espíritus más fuertes y malos han sido los que más han contribuido a la evolución de la humanidad: encendieron una y otra vez las pasiones a punto de adormecerse -toda sociedad ordenada adormece las pasiones- [...] Bajo todas las circunstancias lo nuevo es lo malo, en cuanto es lo que se quiere conquistar, derribar los antiguos mojones y las viejas piedades; iy solo lo viejo es lo bueno! En todo tiempo los hombres buenos son los que ahondan los viejos pensamientos y con ellos rinden frutos; los agricultores del espíritu. Pero toda tierra termina tarde o temprano por quedar agotada, y siempre de nuevo tiene que pasar la reja del mal [...] En realidad, 
empero, los impulsos malos son en un grado igualmente útiles para conservar a la especie e imprescindibles que los buenos: -solo que su función es diferente (Nietzsche, La gaya ciencia 63-4).

Ahora bien, y aquí está el punto de inflexión, Panero no cree en el mal sino que se sitúa, en la estela de Nietzsche, más allá. Podemos así afirmar, sin ningún tipo de reparo, que el amplio despliegue icónico y conceptual del mal en la obra de Leopoldo María Panero cumple un fin meramente estratégico, de subversión, de terrorismo literario si se quiere, con el objetivo no solo de anunciar el fin de un modelo social, sino también el advenimiento de un nuevo tiempo libre de las hipocresías morales. Ese es precisamente el paso: del fin que se acaba en sí mismo al fin que tiene una voluntad de afirmar la destrucción, que hace de la obra paneriana una obra vitalista. El sufrimiento, el dolor terrible que desprenden sus líneas, se ve justificado en pos de un objetivo subversivo, de un ejercicio renovador y revolucionario. Es en esta lectura que hace Panero de Nietzsche en la que al fin hallamos el significado al crepúsculo activo, al asesinato. Panero usa el nihilismo para acabar con el propio nihilismo:

El nihilismo, como fenómeno normal, símbolo de fuerza creciente o de debilidad creciente:

Bien que la fuerza de crear, de querer, haya evolucionado de tal forma que no tenga necesidad de esta interpretación general, de esta introducción de un sentido ("Deberes presentas, Estado, etc.).

O bien que la fuerza creadora que supone el ser disminuya y que la desilusión llegue a ser el estado dominante. La dificultad de creer en su ser, la "incredulidad".

¿Qué significa la ciencia con relación a estas dos posibilidades?

1) Es un signo de fuerza y de dominación de sí mismo, sugiere que se puede prescindir de un mundo, de ilusiones que consuelan y curan las llagas.

2) Pueden también minar sordamente, disecar, desilusionar, debilitar (Nietzsche, La voluntad de poderío 329).

Es en esa fuerza creciente, en esa primera posibilidad donde se expresa, en esa negación de la negación, en que el nihilismo deja de serlo para convertirse en la voluntad de la nada, esto es, en un principio de acción, en contraposición a la reacción:

Ya conocemos el desenlace: el último hombre, el que prefiere una nada de voluntad, apagarse pasivamente, antes que una voluntad de la nada. Pero este desenlace es solo un desenlace para el hombre reactivo, no para la voluntad de la nada. Esta prosigue su empresa, esta vez en silencio, más allá del hombre reactivo. Al romper las fuerzas reactivas su alianza con la voluntad de la nada, la voluntad de la nada a su vez rompe su alianza con las fuerzas reactivas. Inspira al hombre un nuevo placer: destruirse, pero destruirse activamente [...] Zarathustra canta al hombre de la destrucción activa: quiere ser superado, va más allá de lo humano, ya por el camino del superhombre, "franqueando el puente", padre y antepasado de lo sobrehumano (Deleuze 244). 
No cuesta, por tanto, imaginar que esa crueldad activa, esa voluntad de aniquilar, de reducirlo todo a la nada y a la ceniza no es sino una muestra de vitalismo absoluto, de afirmación de la propia vida, una afirmación en la que el instinto liberado, el instinto de destrucción, se impone a la moral, la supera y la reduce a nada al ponerla ante el incontenible goce sexual: "Así pues, el asesinato es siempre un hecho sexual, o lo que es lo mismo, un hecho social: con Artaud, habría que decir que lo mismo nadie se suicida solo, nadie asesina solo" (Panero, Aviso a los civilizados 60). Se convierte, entonces, la crueldad, el crimen, en un acto absoluto y definitivo de la voluntad de poder. Se mata porque se puede, porque Dios ha muerto, y con él una moral única, legislativa y ejecutiva. Se mata porque la propia vida toma el valor que la moral judeocristiana ha querido negarle, se mata por proteger la vida, por instinto de autoconservación:

Los fisiólogos deberían pensárselo bien antes de afirmar que el instinto de autoconservación es el instinto cardinal de un ser orgánico. Algo vivo quiere, antes que nada, dar libre curso a su fuerza -la vida misma es voluntad de poder-: la autoconservación es solo una de las consecuencias indirectas y más frecuentes de esto (Nietzsche, Más allá del bien y del mal 34).

El asesinato es, por tanto, en la escritura paneriana, un principio activo, una muestra de la vida que se rebela ante la posibilidad de una aniquilación de su individualidad, ante una represión de los instintos:

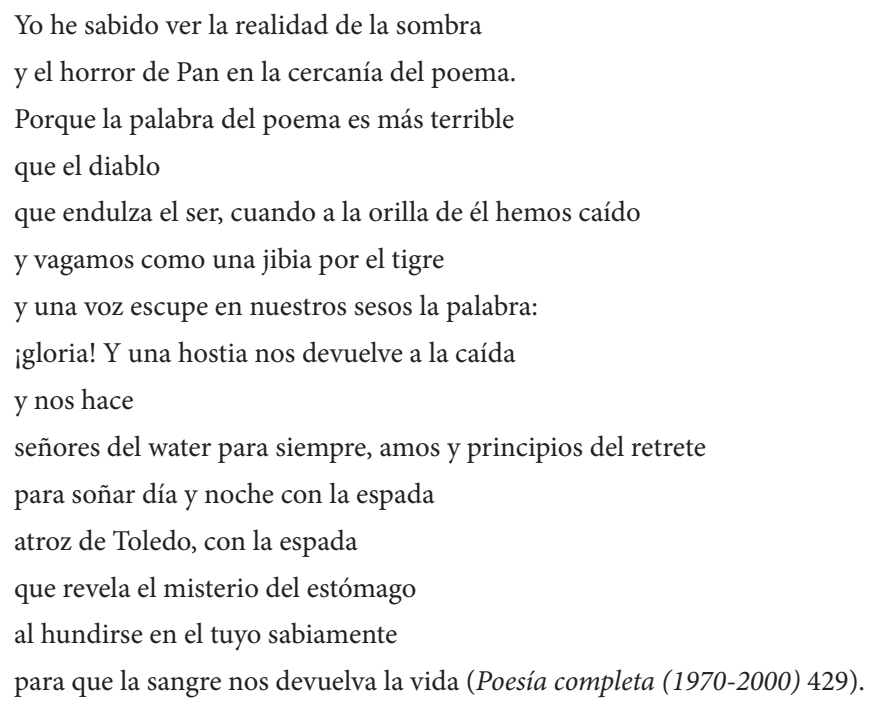

Se nos desvela entonces la clave de la escritura paneriana, la cual anuncia, sí, el fin del orden social, moral, reinante, el final del dominio de los valores ascéticos, el final del nihilismo y de la negación de los instintos:

Ese hombre del futuro, que nos liberará del ideal existente hasta ahora y asimismo de lo que tuvo que nacer de él, de la gran náusea, de la voluntad de la nada, del nihi- 
lismo, ese toque de campana del mediodía y de la gran decisión, que de nuevo libera la voluntad, que devuelve a la tierra su meta y al hombre su esperanza, ese anticristo y antinihilismo, ese vencedor de Dios y de la nada - alguna vez tiene que llegar... (Nietzsche, La genealogía de la moral 161).

El hombre del futuro que Panero, y antes Zaratustra, anuncian, es el hombre que se sitúa más allá del bien y del mal, de una dialéctica que empobrece la vida queriendo reducirla a dos posibilidades: bien/mal, blanco/negro, moral/inmoral, orden/caos. Si hay una imagen que se repite sin cesar en la obra de Leopoldo María Panero es la del hombre que transgrede la ley, que pone su voluntad de vida y su voluntad de destrucción por encima de debilidades morales, de imposiciones, de amenazas:

Para lograr aquel fin se necesitaría una especie de espíritus distinta de los que son probables cabalmente en esta época: espíritus fortalecidos por guerras y victorias, a quienes la conquista, la aventura, el peligro e incluso el dolor se les hayan convertido en una necesidad imperiosa; se necesitaría para ello estar acostumbrados al aire cortante de las alturas, a las caminatas invernales, al hielo y a las montañas en todo sentido, y se necesitaría además una sublime maldad, una última y autosegurísima petulancia del conocimiento, que forma parte de la gran salud, ¡se necesitaría cabalmente, para decirlo pronto y mal, esa gran salud! (Nietzsche, La genealogía de la moral 160-1).

Es, por tanto, el tiempo de los hombres fuertes, de los dioses artistas: el tiempo de Dionisos, que vuelve entre los hombres con la alegría de la danza:

\section{Dyonisos}

Lambda era el grito escrito en las paredes

y el gallo que no hablaba en la basura

escupido en la frente por alguien sin cabeza

mientras un niño, el más oscuro

y cruel y secreto de los niños

susurraba en silencio el nombre del diablo (Poesía completa (1970-2000) 508-9).

Ese nuevo hombre, ese hombre más allá del bien y del mal, no es otro, en la poética del mal de Leopoldo María Panero, que el esquizo, el hombre capaz de cuestionar e imponerse al principio de realidad expresando su propia realidad como muestra de una voluntad de poder:

“Todo es subjetivo", os digo: pero solo al decirlo, nos encontramos una interpretación. El sujeto no nos es dado, sino añadido, imaginado, algo que se esconde. Por consiguiente, ¿se hace necesario contar con una interpretación detrás de la interpretación? En realidad entramos en el campo de la poesía, de las hipótesis.

El mundo es algo "cognoscible", en cuanto la palabra "conocimiento" tiene algún sentido: pero al ser susceptible de diversas interpretaciones, no tiene un sentido fundamental, sino muchísimos sentidos (Nietzsche, La voluntad de poderío 277). 
En efecto, es el esquizo, en tanto que nuevo superhombre, el que hace de la vida una obra de arte, el que estetiza los acontecimientos, el que, en definitiva, hace de su crueldad la gaya ciencia, el trovar de los tiempos que se acaban y los tiempos que tienen que comenzar, el asceta que se extingue y el artista que da un sentido a la existencia, que le imprime un porqué que no está en una realidad extramundana -las ideología s, las utopías, las quimeras religiosas-, sino un sentido terrenal, puesto que no es otra cosa que la reabsorción e interpretación de la realidad:

La interpretación poética o metafórica de la realidad del esquizofrénico o paranoico nos da la clave para penetrar en esos dominios [...] La locura es una estetización de una realidad adversa, y no solo carece de sentido, sino que da función, por ejemplo en la paranoia, es dar sentido a lo que no lo tiene. Igual es la tarea de la conciencia: descifrar, dar, recibir o encontrar sentido, o bien producirlo, como es el caso del arte (Panero, Aviso a los civilizados 26-7).

Así se vuelve a cerrar el círculo: el esquizofrénico, el superhombre, es el principio y el objetivo, es la destrucción y la creación, es lo individual y lo múltiple; pero, sobre todo, es el bien y es el mal. El esquizofrénico es la fuerza de la vida que ha estado reprimida, la sexualidad, los hábitos de conducta, los deseos y los instintos que han sido obligados a humillarse en el prisma de la moralidad, en la criba fatal que destroza lo diferente. El esquizofrénico, en Panero, es el hombre nuevo, porque es el hombre que renace tras su aniquilación, como un ave fénix renovada. El esquizofrénico es el hereje, es el revolucionario, es el poeta maldito, es el ángel caído que se prepara para su victoria, para su apocalipsis. El esquizofrénico es el final de la sociedad y la aurora sangrienta, pero libre, de la obra siempre por venir:

Sí, somos negros: creemos, extendemos el "Mau-Mau”. No con diagnósticos, sino con gritos de guerra. El homo normalis nada puede, ya que es tan solo el esclavo de su apariencia. El psiquiatra nada puede hacer, sino suicidarse. Que no muera la llama. Nunca cedamos en nuestra pretensión no ya de una nueva sociedad, sino de una nueva humanidad. Que sigan hablando, ya no importa. Que sigan excluyendo, nosotros haremos de la uniformidad de esa exclusión, la garantía de una diferente universalidad. Quedáos con vuestros sórdidos secretos, con esa vasta humillación que constituye el mundo de lo privado. De hoy en adelante, hay lugar para un nuevo "nosotros" y un diverso "vosotros". Ya somos, realmente, "nosotros", y "Ellos": ahora veremos quién era el perseguidor y quién el perseguido. Porque os perseguiremos con la misma saña con que vosotros lo hicisteis, aprovechándonos del laberinto de vuestras apariencias, instalados traidoramente entre vosotros sin que sepáis nunca cuál de las marionetas que por allá deambulan mueve ella misma la cuerda. Vosotros, que nos educasteis en el terror a la soledad y la exclusión, sabréis ahora del terror de no estar, nunca jamás, solos (Panero, Aviso a los civilizados 86-7). 


\section{Referencias}

Blesa, Túa. Tránsitos. Escritos sobre poesía. Valencia: Tirant lo Blanch, 2004. Medio impreso. Caro Baroja, Julio. Las brujas y su mundo. Madrid: Alianza Editorial/Ediciones del Prado, 1993. Medio impreso.

Castellet, José $\mathrm{M}^{\mathrm{a}}$., ed. Nueve novísimos poetas españoles. Barcelona: Península, 2001. Medio impreso.

Deleuze, Gilles. Nietzsche y la filosofía. Trad. Carmen Artal. Barcelona: Anagrama, 1999. Medio impreso.

Nietzsche, Friedrich. La genealogía de la moral. Trad. Andrés Sánchez. Madrid: Alianza, 1986. Medio impreso.

---. La gaya ciencia. Trad. C. Greco y G. Groot. Madrid: Akal, 1988. Medio impreso.

---. La voluntad de poderío. Trad. Dolores Castrillo. Madrid: Edaf, 1988. Medio impreso.

---. Más allá del bien y del mal. Trad. Andrés Sánchez. Madrid: Alianza, 1988. Medio impreso.

---. Así habló Zaratustra. Trad. Andrés Sánchez. Madrid: Alianza, 1998. Medio impreso.

---. El Anticristo. Trad. Andrés Sánchez. Madrid: Alianza, 2005. Medio impreso.

---. Crepúsculo de los ídolos. Trad. Andrés Sánchez. Madrid: Alianza, 2005. Medio impreso.

Panero, Leopoldo María. Aviso a los civilizados. Madrid: Libertarias, 1990. Medio impreso.

---. Poesía completa (1970-2000). Madrid: Visor, 2001. Medio impreso.

Ruano, Joaquín. “'La sinagoga de Satanás'. Presencias heréticas en la poesía de Leopoldo María Panero". Castilla. Estudios de Literatura 2 (2011). 123-49. <http://www5.uva. es/castilla/index.php/castilla/article/view/76/70>. Fecha de ingreso: 13 de marzo de 2011. Sitio web. 